Jurnal ABDINUS : Jurnal Pengabdian Nusantara, 2 (2), 2019, 129-142

Available online at: http://ojs.unpkediri.ac.id/index.php/PPM

DOI: https://doi.org/10.29407/ja.v2i2.12575

\title{
Peningkatan Nilai Tambah Pengrajin Dupa Desa Petungsewu Kecamatan Wagir Kabupaten Malang
}

\author{
Endi Sarwoko', Ninik Indawati ${ }^{2}$, Iva Nurdiana ${ }^{3}$, Moh. Ahsan ${ }^{4}$ \\ 1endiswk@unikama.ac.id \\ 1,3 Program Studi Manajemen \\ ${ }^{2}$ Program Studi Pendidikan Ilmu Pengetahuan Sosial \\ ${ }^{4}$ Program Studi Teknik Informatika \\ 1,2,3,4 Universitas Kanjuruhan Malang
}

Received: 0611 2018. Revised: 0911 2018. Accepted: 10012019

\begin{abstract}
Petungsewu Village, Wagir District, Malang Regency is one of the villages where most of the people are incensed craftsmen, but the incense produced is semi-finished incense or raw incense. The problem faced by incense craftsmen is that the selling price of semi-finished incense tends to decline from year to year, the limited bamboo raw material even has to be imported from other areas, only producing semi-finished incense (raw). The aim of the activity is to increase the value added of incense products, and increase people's income by selling incense products with brand packaging. The method of implementing the activity is to diversify the product by training and mentoring in making incense, product packaging training and quality control, online marketing training, utilizing incense making technology. As a result of community service activities, the community is able to produce fragrant incense packaged and branded and has been sold. Besides that, by utilizing incense bamboo making technology, the production capacity of incense biting production increased, the quality of the bamboo produced was more uniform, so the problem of limited incense material could be overcome.
\end{abstract}

Keywords: Craftsmen, Value Added, Training, Community Service

\begin{abstract}
Abstrak: Desa Petungsewu Kecamatan Wagir Kabupaten Malang adalah salah satu desa yang sebagian besar masyarakatnya adalah pengrajin Dupa, tetapi Dupa yang dihasilkan adalah Dupa setengah jadi atau Dupa mentah. Permasalahan yang dihadapi para pengrajin Dupa adalah harga jual Dupa setengah jadi cenderung turun dari tahun ke tahun, keterbatasan bahan baku biting bahkan harus didatangkan dari di daerah lain, hanya memproduksi Dupa setengah jadi (mentah). Tujuan kegiatan pengabdian ini adalah untuk meningkatkan nilai tambah produk Dupa, dan peningkatan pendapatan masyarakat dengan menjual produk Dupa jadi dengan kemasan merek Metode pelaksanaan kegiatan adalah melakukan diversifikasi produk dengan pelatihan dan pendampingan membuat Dupa wangi, pelatihan pengemasan produk dan quality control, dan pelatihan pemasaran online, pemanfaatan teknologi pembuatan biting Dupa. Hasil kegiatan pengabdian, masyarakat mampu menghasilkan Dupa wangi yang dikemas dan diberi merek dan sudah mulai dijual. Selain itu dengan pemanfaatan teknologi pembuatan biting Dupa, kapasitas produksi pembuatan biting Dupa
\end{abstract}




\section{Jurnal ABDINUS : Jurnal Pengabdian Nusantara, 2 (2), 2019, 129-142}

Endi Sarwoko, Ninik Indawati, Iva Nurdiana, Moh. Ahsan

meningkat, kualitas biting yang dihasilkan lebih seragam, sehingga permasalahan keterbatasan bahan biting Dupa dapat diatasi.

Kata kunci: Dupa Wangi, Nilai Tambah, Pelatihan, Pengabdian

\section{ANALISIS SITUASI}

Hasil Sensus Ekonomi Tahun 2016 menunjukkan Jawa Timur menduduki peringkat pertama dari sisi jumlah UKM yaitu sebanyak 4.608.754 unit usaha atau 17,5\% dari jumlah UKM nasional. Terbesar kedua adalah Jawa Barat dengan 4.564.958 unit usaha atau 17,4\% dari jumlah UKM nasional. Demikian pula dilihat dari penyerapan atau jumlah tenaga kerja untuk skala UKM, Jawa Timur merupakan propinsi paling tinggi kemampuan menyerap tenaga kerja di sektor UKM yaitu 11.042.066 orang dari tenaga kerja total 53.641.524 orang untuk seluruh Indonesia, jadi di Jawa Timur mampu menyerap 20,6\% tenaga kerja sektor UKM dibandingkan seluru propinsi di Indonesia. Terbesar kedua adalah propinsi Jawa Barat dengan jumlah 8.486.372 tenaga kerja atau sebesar 16\% (Badan Pusat Statistik Indonesia, 2017).

Kabupaten Malang memiliki potensi pertumbuhan ekonomi yang menjanjikan karena memiliki jumlah usaha mikro kecil dan menengah (UMKM) yang banyak dan mampu menyerap tenaga kerja. Salah satu usaha mikro kecil di Kabupaten Malang adalah produksi Dupa yang ada di wilayah Kecamatan Wagir, dimana sebagian besar masyarakatnya adalah para pengrajin Dupa. Jumlah UMKM banyak menjadi penyumbang pertumbuhan ekonomi karena peran pokok usaha kecil adalah sebagai penyerap tenaga kerja, sebagai penghasil barang dan jasa pada tingkat harga yang terjangkau bagi kebutuhan rakyat banyak yang berpenghasilan rendah, sebagai penghasil devisa negara yang potensial kerena keberhasilannya dalam meproduksi komoditi ekspor non migas (Glendoh, 2001; Sarwoko, 2013).

Permasalahan yang dihadapi para pengrajin Dupa di Desa Petungsewu adalah hanya memproduksi Dupa setengah jadi sehingga nilai tambahnya rendah, proses produksi secara manual, harga jual Dupa setengah jadi cenderung turun dari tahun ke tahun, keterbatasan bahan baku biting bahkan harus didatangkan dari di daerah lain. Dupa yang dihasilkan masyarakat Desa Petungsewu adalah Dupa mentah atau Dupa setengah jadi yang belum diberi pewangi. Pemasarannya adalah ke Pulau Bali melalui beberapa distributor atau pengepul. Dupa setengah jadi tersebut oleh pengusaha di Bali diberi pewangi, dikemas dan dijual dengan merek mereka. Karena Dupa yang dihasilkan masih setengah jadi maka harga jual 


\section{Jurnal ABDINUS : Jurnal Pengabdian Nusantara, 2 (2), 2019, 129-142 \\ Endi Sarwoko, Ninik Indawati, Iva Nurdiana, Moh. Ahsan}

relatif murah bahkan dengan ketatnya persaingan maka harga jual cenderung turun dari tahun ke tahun. Selain permasalahan tersebut, pemenuhan kebutuhan bahan baku biting untuk pembuatan Dupa juga masih harus didatangkan dari luar daerah, padahal di Desa Petungsewu juga banyak para pengrajin biting. Hal ini disebabkan karena proses pembuatan biting untuk Dupa semuanya dilakukan secara manual sehingga kapasitas produksinya terbatas.

\section{SOLUSI DAN TARGET}

Pemecahan masalah yang dilaksanakan pada kegiatan pengabdian ini terkait dengan peningkatan nilai tambah produk Dupa yaitu dengan memberikan pelatihan dan pendampingan kepada pengrajin Dupa di Desa Petungsewu, serta penerapan teknologi sederhana pembuatan biting Dupa. Pelatihaan yang dilaksanakan meliputi pelatihan pembuatan Dupa wangi, pelatihan pengemasan dan quality control, pelatihan pemasaran online.

Pelaksanaan kegiatan pengabdian ini bertujuan untuk meningkatkan nilai tambah produk Dupa di Desa Petungsewu, peningkatan pendapatan masyarakat dengan menjual produk Dupa jadi dengan kemasan merek, peningkatan produksi biting Dupa dengan penerapan teknologi sederhana. Dilihat dari harga jual antara Dupa setengah jadi dengan Dupa jadi yang sudah diberi pewangi dan dikemas cukup besar, sehingga sebenarnya ada peluang peningkatan nilai tambah produksi Dupa jika masyarakat mampu untuk menghasilkan Dupa wangi. Dampak dari peningkatan nilai tambah tentunya pendapatan masyarakat pengrajin Dupa juga akan meningkat.

\section{METODE PELAKSANAAN}

Pemecahan masalah yang dilaksanakan pada kegiatan pengabdian ini terkait dengan peningkatan nilai tambah produk Dupa adalah dengan memberikan pelatihan dan pendampingan kepada pengrajin Dupa di Desa Petungsewu, serta substitusi iptek yaitu penerapan teknologi alat/mesin pembuatan Dupa dan mesin pembuatan biting Dupa.

1. Pelatihan

Kegiatan pelatihan dimaksudkan untuk memberikan bekal praktik kepada para pengrajin Dupa di Desa Petungsewu yang selama ini sudah membuat Dupa mentah agar bisa melanjutkan produksi menjadi Dupa wangi, untuk dikemas dan dijual menjadi produk jadi dan diberi merek. Penerapan merek terhadap produk UKM dapat memudahkan konsumen memilih produk ditengah banyaknya pilihan produk. Penggunaan merek yang 


\section{Jurnal ABDINUS : Jurnal Pengabdian Nusantara, 2 (2), 2019, 129-142}

Endi Sarwoko, Ninik Indawati, Iva Nurdiana, Moh. Ahsan

tepat pada produk memudahkan produk UKM masuk ke pasar nasional, dan dapat meningkatkan penetrasi. Kemasan dengan desain menarik dan label yang informatif dapat menentukan minat konsumen membeli produk tersebut (Nugraha, 2017).

Para pengrajin Dupa di Desa Petungsewu belum mengetahui bahwa harga jual Dupa wangi yang sudah dikemas jauh lebih tinggi dari harga Dupa mentah yang selama ini mereka jual. Selain itu para pengrajin Dupa di Desa Petungsewu juga belum mengetahui aroma apa yang diterima atau laku di pasar. Materi pelatihan pembuatan Dupa wangi memberikan informasi harga Dupa wangi di pasar Bali, selain melatih tahapan pemberian aroma pewangi pada Dupa mentah. Pelatihan juga memberikan cara memilih dan melakukan pencampuran cairan aroma sebelum digunakan sebagai aroma pewangi Dupa. Pelatihaan yang dilaksanakan dalam pengabdian kepada masyarakat ini meliputi pelatihan pembuatan Dupa wangi, pelatihan pengemasan dan quality control, pelatihan pemasaran online.

a. Pelatihan pembuatan Dupa wangi

Pelatihan pembuatan Dupa wangi merupakan upaya melakukan diversifikasi produk Dupa. Kegiatan pelatihan dimaksudkan untuk memberikan bekal praktik kepada para pengrajin Dupa di Desa Wagir yang selama ini sudah membuat Dupa mentah agar bisa melanjutkan produksi menjadi Dupa wangi, untuk dikemas dan dijual menjadi produk jadi dan diberi merek. Penerapan merek terhadap produk UKM dapat memudahkan konsumen memilih produk ditengah banyaknya pilihan produk. Penggunaan merek yang tepat pada produk memudahkan produk UKM masuk ke pasar nasional, dan dapat meningkatkan penetrasi. Kemasan dengan desain menarik dan label yang informatif dapat menentukan minat konsumen membeli produk tersebut (Nugraha, 2017).

Para pengrajin Dupa di desa Petungsewu belum mengetahui bahwa harga jual Dupa wangi yang sudah dikemas jauh lebih tinggi dari harga Dupa mentah yang selama ini mereka jual. Selain itu para pengrajin Dupa di desa Petungsewu juga belum mengetahui aroma apa yang diterima atau laku di pasar. Materi pelatihan pembuatan Dupa wangi memberikan informasi harga Dupa wangi di pasar Bali, selain melatih tahapan pemberian aroma pewangi pada Dupa mentah. Pelatihan juga memberikan cara memilih dan melakukan pencampuran cairan aroma sebelum digunakan sebagai aroma pewangi Dupa. 


\section{Jurnal ABDINUS : Jurnal Pengabdian Nusantara, 2 (2), 2019, 129-142}

Endi Sarwoko, Ninik Indawati, Iva Nurdiana, Moh. Ahsan

Agar kegiatan pelatihan memiliki hasil nyata bagi para pelaku usaha Dupa di desa Petungsewu, maka dilanjutkan dengan kegiatan praktik pembuatan Dupa wangi pada masing-masing kelompok. Pembuatan Dupa wangi di sini adalah teknik atau cara pemberian aroma pada Dupa setengah jadi yang selama ini mereka produksi.

b. Pelatihan pengemasan dan quality control

Pelatihan pengemasan dan quality control sebagai tahapan lanjutan dari pelatihan pembuatan Dupa wangi juga diberikan kepada para pengrajin Dupa di Desa Petungsewu. Tujuan pelatihan pengemasan dan quality control adalah agar para pengrajin Dupa yang sudah menghasilkan Dupa wangi, mampu membuat kemasan yang menarik disertai label merek. Materi pelatihan juga menjelaskan bagaimana cara membuat kemasan dengan biasa yang murah namun hasilnya menarik dari beragam bahan plastik. Berbeda dengan Dupa mentah atau setengah jadi, dimana orientasi para pengrajin adalah pada berat Dupa, jika Dupa wangi (jadi) maka penekanan pada kualitas yang menjadi hal yang penting, oleh karena itu pelatihan juga memberikan materi tentang bagaimana menjaga kualitas produk, mulai dari ukuran yang seragam, kehalusan Dupa, dan bagaimana memilih biting Dupa yang bagus.

c. Pelatihan pemasaran online

Pelatihan pemasaran online diberikan bertujuan untuk memberikan alternatif solusi dari para pengrajin Dupa di Desa Petungsewu tentang mudahnya melakukan pemasaran secara online. Mindset yang berkembang dari para pengrajin Dupa selama ini adalah kesulitan memasarkan produk jadi dibandingkan dengan produk mentah. Pemasaran online pada prinsipnya para pengrajin mempromosikan produknya dengan biaya murah, dengan hanya mengandalkan smartphone dan nomor kontak. Pemasaran online bisa dipilih karena memiliki manfaat dan keuntungan sebagai media promosi dalam rangka untuk meningkatkan volume penjualan (Supardi, 2009; Jansen, 2006). Penggunaan teknologi internet memberikan manfaat pemasaran atau penjualan produk dapat dilakukan kapanpun dimanapun sehingga tidak terikat ruang dan waktu (Jinling, 2009). Guna melengkapi serangkaian kegiatan pelatihan dan pendampingan pada para pengrajin Dupa di Desa Petungsewu, juga diberikan sosialisasi dan pendampingan tentang cara pendaftaran merek. Hal ini dimaksudkan jika para pengrajin sudah menghasilkan Dupa wangi maka perlu diberi label merek sebelum dipasarkan, merek tersebut harus didaftarkan sebagai hak milik dari pengrajin. 


\section{Jurnal ABDINUS : Jurnal Pengabdian Nusantara, 2 (2), 2019, 129-142}

Endi Sarwoko, Ninik Indawati, Iva Nurdiana, Moh. Ahsan

2. Substitusi Ipteks

Metode lain dalam kegiatan pengabdian kepada masyarakat ini adalah dengan metode substitusi ipteks berupa:

a. Mesin Dupa sederhana

Mesin Dupa sederhana merupakan penerapan teknologi pembuatan Dupa dari cara manual menjadi semi otomatis. Alat yang digunakan untuk pembuatan Dupa ini dikenal dengan mesin/alat "gopyok" yaitu alat untuk melekatkan serbuk kayu bahan Dupa ke biting/lidi Dupa. Tujuan penerapan alat ini adalah untuk meningkatkan kapasitas produksi pembuatan Dupa, karena proses produksi lebih cepat dibandingkan dengan tenaga manusia.

b. Mesin pembuat biting

Selama ini pengrajin biting di wilayah Desa Petungsewu dilakukan secara manual tenaga manusia, oleh karena itu kapasitas produksi tidak bisa memenuhi kebutuhan biting Dupa di Desa Petungsewu. Guna meningkatkan kapasitas produksi biting maka diterapkan teknologi berupa mesin rajang dan serut bambu. Mesin rajang digunakan untuk membelah bambu menjadi biting, sedangkan serut digunakan untuk menghaluskan.

\section{HASIL DAN LUARAN}

Hasil identifikasi masalah di lapangan bahwa masyarakat Desa Petungsewu hanya memproduksi Dupa mentah, padahal jika dilanjutkan dengan tahapan diolah menjadi Dupa wangi maka harga jual jauh lebih mahal. Diversifikasi produk berupa pembuatan Dupa wangi merupakan salah satu kegiatan untuk meningkatkan nilai tambah produk Dupa, sehingga pendapatan pengrajin Dupa meningkat.

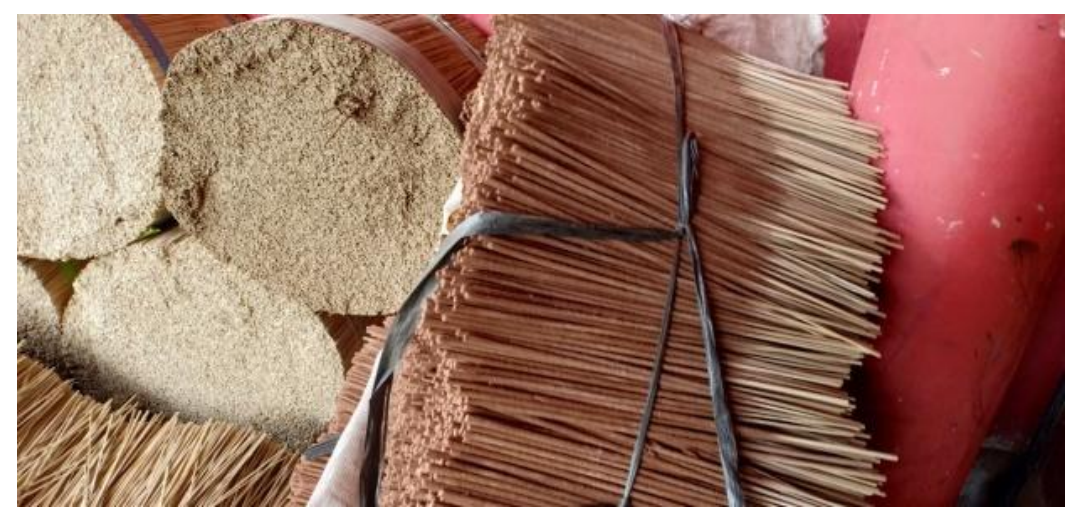

Gambar 1. Dupa setengah jadi (mentah) 
Pelatihan pembuatan Dupa wangi mampu memberikan keterampilan kepada para pengrajin Dupa untuk membuat Dupa wangi. Modal yang dibutuhkan relatif kecil karena hanya membutuhkan cairan aroma pewangi dan kemasan dari bahan plastik. Harga Dupa setengah jadi berada di kisaran harga Rp 12.000/kg, sedangkan harga Dupa wangi yang sudah dikemas mencapai Rp 25.000/kg. Tambahan biaya yang dibutuhkan untuk bahan pewangi dan kemasan, serta biaya operasional untuk $1 \mathrm{~kg}$ tidak lebih dari Rp 5.000/kg, sehingga ada nilai tambah $\mathrm{Rp}$ 8.000/kg. Peluang peningkatan nilai tambah inilah yang dicapai dari proses pembuatan Dupa wangi pada kegiatan pengabdian ini.

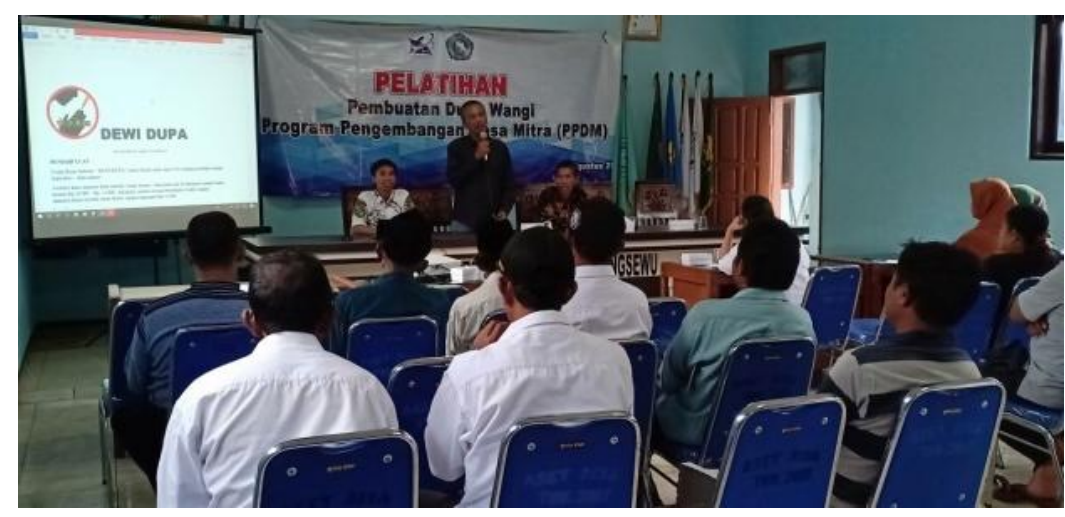

Gambar 2. Pelatihan pembuatan Dupa wangi

Jenis-jenis aroma untuk produksi Dupa wangi disesuaikan dengan selera dari masyarakat pengguna, dalam hal ini karena pemasaran Dupa wangi ke Bali maka beberapa jenis aroma yang disukai antara lain aroma cendana, cempaka, melati, jempiring, mawar, kamboja, maharaja, saiflora, pudak wangi, kawie, nectar, gaharu, canangsari, khrisna, dan rastra. Banyaknya jenis aroma disebabkan selain karena permintaan tetapi juga setiap daerah cenderung menyukai jenis aroma tertentu sehingga kita pengrajin harus kreatif menciptakan jenis-jenis aroma. Setiap produsen Dupa wangi mempunyai ciri khas tersendiri di setiap aroma, mungkin dengan nama yang sama tapi berbeda aromanya, inilah yang menjadi tantangan tersendiri jika memproduksi Dupa wangi.

Proses pemberian pewangi Dupa biting secara tradisional dibagi menjadi 2 yaitu:

1. Sistem celup

Prosesnya Dupa yang sudah kering, dicelupkan pada bahan pewangi. Proses celupnya bisa setengah batang atau penuh satu batang, tergantung kualitas yang dikehendaki. Harga Dupa celup setengah batang tentunya lebih murah dibandingkan celup penuh. 


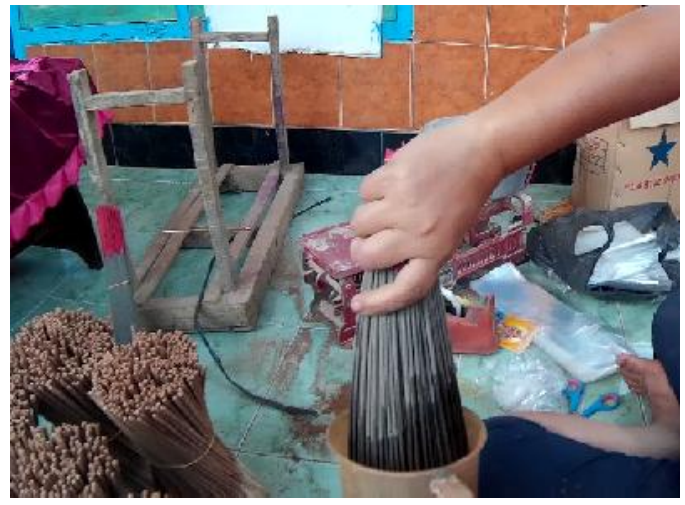

Gambar 3. Proses pemberian pewangi sistem celup

Kelebihan pemberian pewangi Dupa dengan sistem celup, aroma yang dihasilkan lebih kuat dan tahan lama dibandingkan dengan sistem semprot. Namun juga memiliki kelemahan, kebutuhan cairan pewangi lebih banyak dibandingkan sistem semprot.

2. Sistem semprot

Sesuai dengan namanya, sistem ini pewangi disemprotkan ke Dupa setengah jadi dengan alat sprayer yang biasanya digunakan untuk merawat bunga. Proses dimulai dengan mengikat Dupa (biasanya per $1 \mathrm{Kg}$ atau segenggam), setelah diikat diberdirikan seperti pada gambar 4. Lakukan proses semprot dari atas ke bawah merata untuk satu ikatan.

Harga Dupa semprot pada umumnya bisa lebih murah dibandingkan dengan Dupa celup namun ada juga yang lebih mahal, tergantung pada kualitas pewangi/aroma. Biasanya untuk aroma yang bahan bakunya mahal, pengrajin Dupa memilih sistem semprot untuk menghemat bahan, dengan hasil kualitas Dupa aromanya bagus.

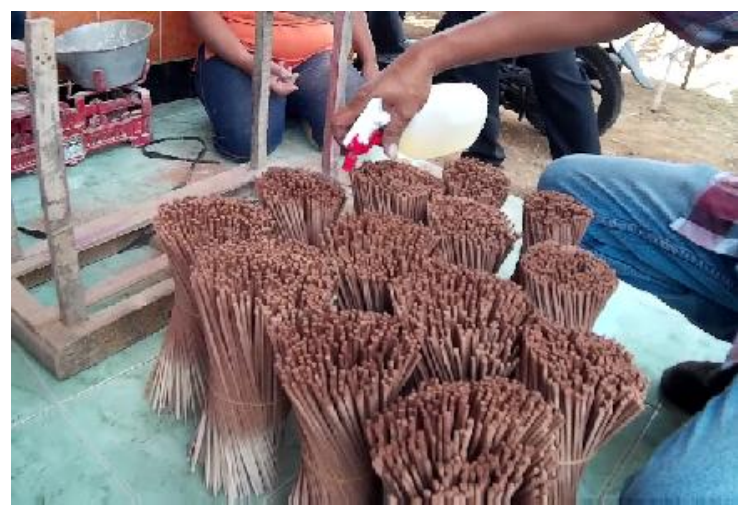

Gambar 4. Proses pemberian pewangi sistem semprot

Kelebihan proses pemberian aroma Dupa dengan sistem semprot karena tidak seluruh bagian Dupa disemprot secara merata yaitu bisa dilakukan penghematan bahan aroma, namun kelemahannya aroma yang dihasilkan pada saat Dupa dibakar tidak terlalu kuat, dan aromanya cepat habis. 


\section{Jurnal ABDINUS : Jurnal Pengabdian Nusantara, 2 (2), 2019, 129-142 \\ Endi Sarwoko, Ninik Indawati, Iva Nurdiana, Moh. Ahsan}

Jenis Dupa wangi dan cara pemberian aromanya terbagi menjadi 4 yaitu:

1. Sekedar wangi atau sering disebut SW

Dupa jenis ini adalah kualitas terendah dalam kelas Dupa wangi, karena aroma pengharumnya hanya di ujung Dupa sekitar $3-5 \mathrm{~cm}$ dari atas, selebihnya aromanya tidak terlalu kuat. Permintaan Dupa jenis ini tergolong tinggi karena sering digunakan oleh masyarakat bawah atau konsumen rumahan sebagai Dupa harian. Teknik pemberian aroma pada Dupa ini adalah sistem semprot. Bahan yang di gunakan adalah biang parfum dan pelarut. Komposisinya tergantung dengan produk biang parfum, semakin baik kualitas biang parfum semakin sedikit yang digunakan.

Cara penyemprotan parfum ke Dupa adalah:

a. Ikat dengan karet gelang untuk berat 1 kilogram Dupa mentah dan berdirikan, lalu semprotkan secara perlahan aroma yang sudah disiapkan dengan hand sprayer dari atas secara merata, turun ke bawah sampai sekitar $3 \mathrm{~cm}$, proses penyemprotan ini diulang 1 kali. Harga Dupa sekedar wangi saat ini berkisar Rp. 35.000 - Rp. 40.000/kg

b. Penggunaan atau pemakaian 1 liter pewangi untuk bisa digunakan untuk $30 \mathrm{~kg}$ Dupa mentah.

2. Spesial Kering (SK)

Dupa jenis ini beraroma penuh dari atas sampai bawah, atau pada saat dibakar aromanya merata mulai dari ujung Dupa sampai kaki Dupa, kekuatan wanginya sama dengan Dupa SW, hanya berbeda komposisi bahannya. Teknik pemberian aroma Dupa spesial kering adalah semprot penuh dari ujung Dupa sampai batas kaki Dupa, dengan langkah-langkah:

a. Pegang kaki Dupa secukupnya lalu dikembangkan, selanjutnya dilakukan penyemprotan secara merata.

b. Penggunaan atau pemakaian pewangi 1 liter dapat digunakan untuk 15 kilogram Dupa mentah, walaupun bahan pewangi yang digunakan lebih banyak namun harga jualnya akan berbeda dengan Dupa sekedar wangi, saat ini harga Dupa spesial kering berkisar Rp.35.000 - Rp. 40.000/kg.

3. Spesial basah/Dupa basah (Premium)

Dupa basah satu tingkat di atas Dupa special kering, dengan ciri aromanya kuat dan waktu bakarnya lebih lama dari jenis Dupa special kering. Dupa special basah sangat berbeda cara pewangian dengan 2 jenis Dupa sebelumnya yaitu komposisi parfum 2 kali lipat dari yang digunakan untuk Dupa SW dan SK serta ada tambahan minyak basah 
untuk menambah jangka waktu pembakaran, sehingga dengan ukuran Dupa yang sama kita bisa mendapatkan waktu bakar yang lebih lama. Proses pemberian aromanya dengan sistem celup. Penggunaan atau pemakaian pewangi 1 liter hanya bisa digunakan untuk 1,5 kg Dupa karena untuk special basah Dupa harus dicelup kurang lebih 1 - 2 jam, sehingga pewanggi yang digunakan cukup banyak. Saat ini kisaran harga untuk Dupa basah antara Rp. 85.000 - Rp. 100.000/kg. Untuk kemasan Dupa Special Basah umumnya digunakan kemasan kecil karena harga cukup tinggi.

4. Istimewa

Jenis ini merupakan jenis Dupa kualitas atas, namun Dupa jenis ini kemampuan pasarnya cukup terbatas karena hanya di gunakan masyarakat tertentu disamping harganya cukup mahal. Proses pemberian aroma sama dengan kualitas spesial, hanya berbeda pada jenis parfumnya dengan kualitas yang paling baik.

Selain pemberian pelatihan pembuatan Dupa wangi, juga diberikan pelatihan tentang pengemasan dan quality control dari Dupa yang akan dijual. Kemasan yang biasa digunakan untuk Dupa jadi adalah plastik atau kertas. Bentuk kemasan dan berat Dupa dalam satu kemasanpun tergantung pada kualitas Dupa yang dihasilkan. Untuk Dupa SW digunakan kemasan diikat per $1 \mathrm{~kg}$ dengan kemasan berupa plastik diberi label merek ditutup pakai stiker/isolasi. Semakin mahal jenis Dupa yang dijual, berat Dupa dalam kemasan semakin sedikit/ringan, hal ini dimaksudkan agar harga jual Dupa eceran tidak terlalu mahal.

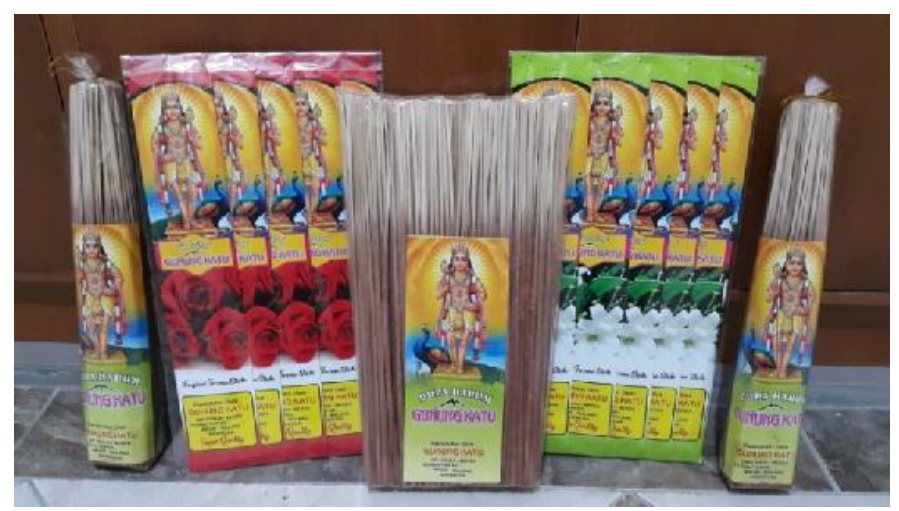

Gambar 5. Hasil Dupa Wangi Kemasan

Apabila pengrajin Dupa memproduksi Dupa jadi, faktor penting adalah menjaga quality control baik kehalusan dan keseragaman bentuk Dupa, maupun kerapian biting Dupa. Hal ini disebabkan Dupa yang dihasilkan adalah Dupa manual (non mesin). Jika Dupa mesin ukuran Dupa dan bentuk biting pasti sudah bagus. Quality control ini harus dijaga karena di pasaran menghadapi berbagai merek Dupa sejenis, konsumen biasanya memilih Dupa karena 
aromanya cocok, namun jika aroma sudah diterima konsumen, namun kualitas Dupanya tidak rapi maka konsumen akan memilih Dupa merek lain.

Salah satu kunci keberhasilan suatu usaha adalah bagaimana memasarkan produk yang dihasilkan. Sebagus apapun produk yang dihasilkan tetapi pengusaha tidak memiliki kemampuan menjual akan sia-sia. Oleh karena itu para pengrajin Dupa Desa Petungsewu dibekali juga bagaimana membuat lapak online untuk memposting Dupa wangi yang dihasilkannya. Hasil pelatihan sebanyak 4 pemilik usaha Dupa sudah berhasil membuat lapak online di Bukalapak.com dan sudah mengisi produk Dupa wangi yang dihasilkan.

Salah satu kelemahan dalam pengelolaan usaha mikro dan kecil di Indonesia adalah belum mengetahui akan pentingnya pendaftaran merek atau label produk. Oleh karena itu pengrajin Dupa yang sudah memiliki label merek telah difasilitasi untuk dilakukan pendaftaran merek, yaitu merek "Dupa wangi GUNUNG KATU”, dan merek "Dewi Dupa”. Sesuai dengan permasalahan yang ada khususnya ketersediaan biting yang harus didatangkan dari kota lain, maka perlu dilakukan peningkatan produksi biting, dengan pemanfaatakan alat rajang dan serut bambu.

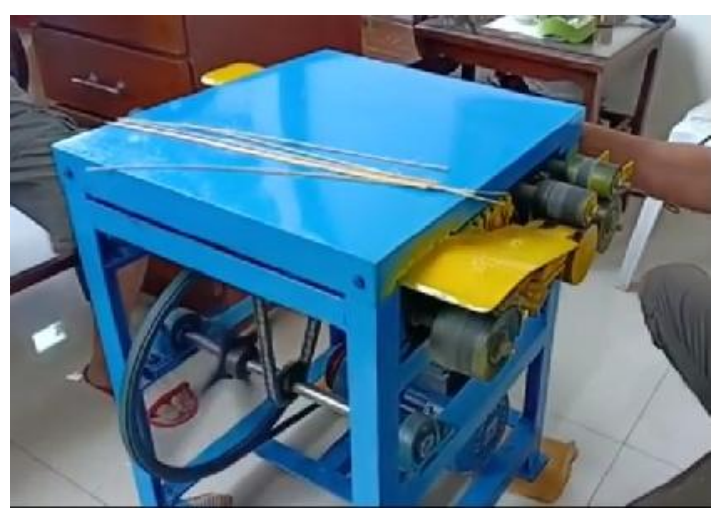

Gambar 6. Mesin rajang bambu

Alat ini berfungsi untuk memecah bambu batangan menjadi belahan-belahan kecil. Selanjutnya dari belahan tersebut dibelah-belah lagi menjadi bagian yang lebih kecil (istilah Bahasa Jawa "di rajang") sesuai ukuran yang dikehendaki. Ukuran paling kecil adalah untuk biting Dupa, sedangkan yang lebih besar adalah untuk biting sate. Proses perajangan bambu ini selesai tahap berikutnya adalah dijemur. 


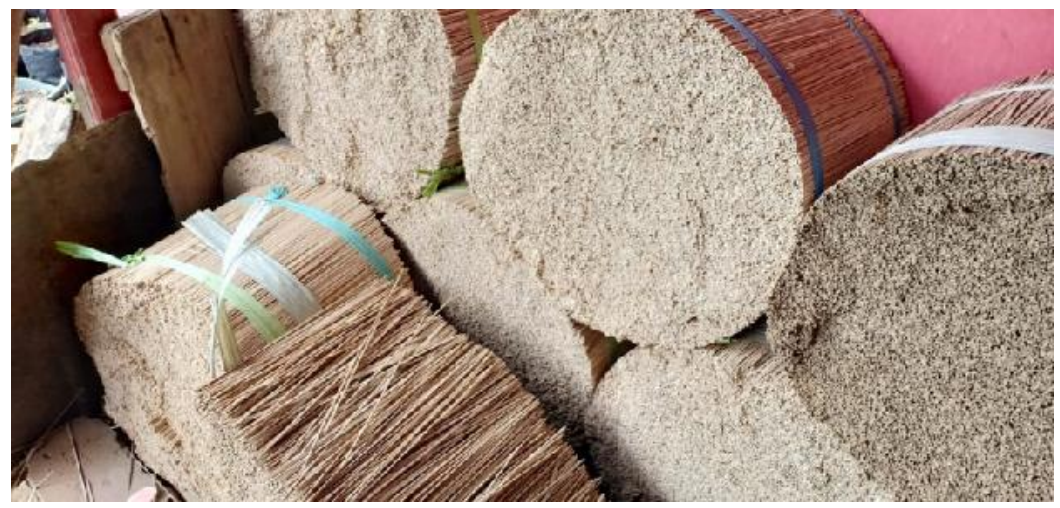

Gambar 7. Hasil produksi biting dengan alat

Kapasitas produksi biting dengan menggunakan mesin rajang dan gesek adalah 50 $\mathrm{kg} / \mathrm{jam}$ sedangkan cara manual pengrajin biting maksimal mampu menghasilkan $70 \mathrm{~kg} / \mathrm{hari}$ atau $14 \mathrm{~kg} / \mathrm{jam}$ untuk tenaga kerja 2 orang. Per hari rata-rata pengrajin biting mengalokasikan waktu 5 jam untuk produksi maka per hari para pengrajin mampu menghasilkan $250 \mathrm{~kg}$ dengan menggunakan mesin ini, jadi ada peningkatan produksi sekitar $180 \mathrm{~kg} / \mathrm{hari}$. Jika dihitung dalam Rupiah, cara manual produksi rata-rata $70 \mathrm{~kg} /$ hari dan harga jual $\mathrm{Rp} 3.500 / \mathrm{kg}$ didapatkan pendapatan kotor Rp 245.000/hari. Jika menggunakan mesin dengan produksi Rp $250 \mathrm{~kg}$ dengan harga jual sama diperoleh pendapatan kotor $\mathrm{Rp} \mathrm{875.000/hari,} \mathrm{sebelum}$ dikurangi biaya-biaya tambahan seperti biaya listrik dan perawatan mesin. Biaya listrik per bulan yang diperlukan selama penggunaan mesin adalah $\mathrm{Rp}$ 400.000. Sehingga penggunaan mesin pengolah bambu untuk biting lebih menguntungkan karena dihasilkan kapasitas produksi dan pendapatan lebih besar dari cara manual.

Peningkatan produksi biting harus dibarengi juga dengan peningkatan kapasitas produksi Dupa, yaitu dengan pemanfaatan mesin "gopyok" fungsinya untuk menempelkan serbuk kayu bahan Dupa ke biting. Mesin digerakkan dengan tenaga listrik, daya listrik bisa disesuaikan dengan kebutuhan dengan daya 400 watt sampai 1000 watt.

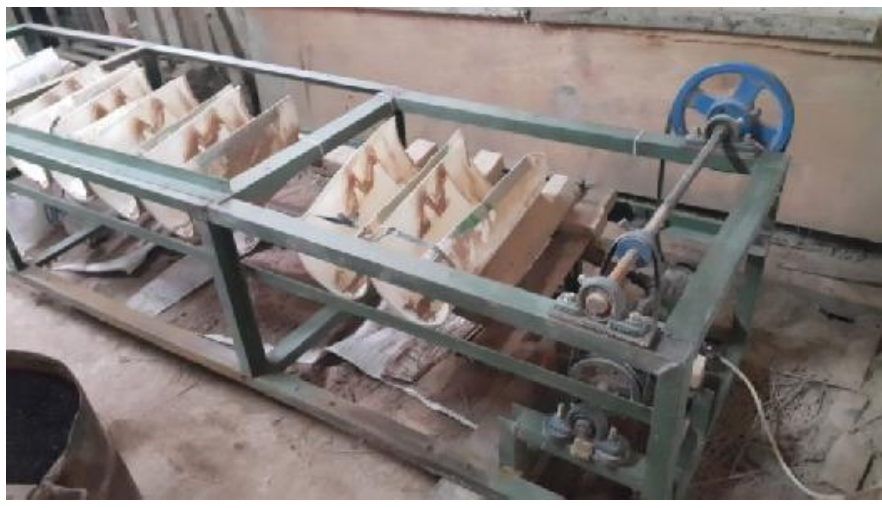

Gambar 8. Mesin Gopyok Dupa 


\section{Jurnal ABDINUS : Jurnal Pengabdian Nusantara, 2 (2), 2019, 129-142}

Endi Sarwoko, Ninik Indawati, Iva Nurdiana, Moh. Ahsan

Penggunaan mesin Gopyok mampu meningkatkan kapasitas produksi Dupa setengah jadi dari $30 \mathrm{~kg} /$ hari menjadi $90 \mathrm{~kg} / \mathrm{hari}$, ada peningkatan $60 \mathrm{~kg}$ atau peningkatan pendapatan kotor $60 \mathrm{~kg}$ x $\mathrm{Rp} 12.000=\mathrm{Rp} 720.000$ (sebelum dikurangi biaya listrik). Kelebihan penggunaan alat gopyok dalam pembuatan Dupa adalah kapasitas produksi lebih banyak dibandingkan cara manual sedangkan kelemahannya adalah membutuhkan tambahan biaya karena penggunaan daya listrik. Jadi penggunaan mesin/alat ini sangat cocok untuk pengembangan usaha atau peningkatan kapasitas produksi, sehingga cara manual tetap dilakukan dikombinasi dengan alat.

\section{SIMPULAN}

Kegiatan pengabdian berupa peningkatan nilai tambah produk Dupa untuk warga Desa Petungsewu ini membawa manfaat.

1. Pengrajin Dupa memiliki tambahan produk jadi berupa Dupa wangi dengan kualitas SW. Pilihan produksi Dupa kualitas SW karena Dupa jenis ini permintaannya banyak, karena digunakan oleh masyarakat umum untuk kebutuhan harian.

2. Pendapatan masyarakat meningkat, karena harga Dupa wangi jauh lebih tinggi dibandingkan Dupa setengah jadi (tanpa pewangi). Pengrajin Dupa jadi mendapatkan tambahan pendapatan bersih sekitar Rp 8.000/kg dibandingkan jika dijual setengah jadi. Selain itu peningkatan pendapatan juga bisa diperoleh dari peningkatan kapasitas produksi biting dengan penggunaan alat sebesar Rp 12.000/kg.

3. Peningkatan nilai tambah produk Dupa, karena masyarakat tetap memproduksi Dupa manual dan dijual setengah jadi, sekarang memiliki tambahan produksi berupa Dupa wangi.

\section{DAFTAR RUJUKAN}

Badan Pusat Statitik Indonesia, http://bps.go.id diakses Desember 2017.

Glendoh, Sentor Harman, (2001). Pembinaan dan Pengembangan Usaha Kecil, Jurnal Manajemen \& Kewirausahaan. Vol. 3 No. 1.p. 1-13.

Jansen, B.J. (2006). The Comparative Effectiveness of Sponsored and Nonsponsored Links for Web E-commerce Queries. ACM Transactions on the Web, Vol. 1, No. 1, May 2006. Jinling, Chang et all. (2009). Modeling E-Commerce Website Quality with Quality Function Deployment, IEEE International Conference on Deployment e-Business Engineering. 21-23 Oct. 
Nugraha, H.S., Ariyanti, F., Darwanto, (2017). Penerapan Branding pada Makanan Ringan di Kabupaten Jepara. Jurnal Administrasi Bisnis. Vol. 6, No. 1

Sarwoko, E., Surachman, and Armanu, (2012). Entrepreneurial Characteristics and Competency as Determinants of Business Performance in SMEs. IOSR Journal of Business and Management, Vol. 7 Issue 3.

Supardi, Julian. (2009). Rancang Bangun Collaborative System Pemasaran Hotel Secaraonline Dengan Pendekatan Mediator based. Jurnal Sistem Informasi Fasilkom Unsri. Vol 1 No 2 . 